\title{
Transformer(s) of the Logistics Industry - Enabling Logistics Companies to Excel with Digital Platforms
}

\author{
Barbara Steffen \\ TU Dortmund University \\ Barbara.Steffen@tu-dortmund.de
}

\author{
Frederik Möller \\ TU Dortmund University, \\ Fraunhofer ISST \\ Frederik.Moeller@tu-dortmund.de
}

\author{
Lisa Nowak \\ TU Dortmund University \\ Lisa.Nowak@tu-dortmund.de
}

\begin{abstract}
Platformization is a prevailing trend that changes industries at their core. The rise and dominance of platform-based companies require incumbent companies and start-ups to rethink how they approach that novel challenge and leverage its full potential. To successfully steer and initiate this digitally enabled industry transformation, even in traditional industries like logistics, the incumbent companies require IT and specific platform design support. However, designing a digital platform is a complex task riddled with design options, potential pitfalls, and complex underlying mechanisms. Consequently, research and practice require tools to leverage past design knowledge and generate digital platforms in a goal-oriented fashion. This paper addresses precisely that issue as we report on a design science research study that developed a visual inquiry tool for digital platform design. Ultimately, the visual inquiry tool provides researchers and practitioners with the means to develop digital platforms more efficiently and strategically.
\end{abstract}

\section{Introduction}

Today, most industries' high-tech economic disruption is driven by platformization [1, 2]. Platformization takes place in all kinds of industries and markets as it eases transactions and allows for innovation at a large scale [3]. This trend leads to a 'platformania' [4, 5], a significant increase in platforms on the market. The question remains whether industries get disrupted by potential entrants or by incumbent companies defending their market shares with their own digital platforms. Companies experience increasing pressure to become their industries' first-mover, securing network effects and establishing barriers to prevent followers' entry [2]. Being first does not ensure success, but being late can be deadly. Some even argue that all companies - even traditional companies - must become platform companies to survive $[6,7]$. However, an analysis by Yoffie et al. [4] shows that developing a successful platform is more complicated than expected. 209 out of 252 analyzed American platforms failed. To successfully steer through the heterogeneous landscape of digital platform concepts, it is crucial to understand their design phenomenology, i.e., the platform's composition and design steps [8].

IT support and business model adaptation guidance are relevant to enable incumbent companies to drive the industry transformation via digital platforms, i.e., a competitive strategy [7]. This enablement is precisely the aim of this paper's case study.

Based on our own experiences and discussions with industry experts, the European logistics industry barely invested in digitalization and, subsequently, lags behind in most topics associated with it. That notion is corroborated by existing, recent studies, which find a significant and urgent need for logistics companies to adapt to digitalization and its technologies [9]. Thus, only very few industry-wide standards exist, hindering the compatibility of solutions like, e.g., industry-wide track \& trace and data exchange solutions. To tackle this issue and achieve industry transformation, a German state-funded project supports digital platform development via developing and offering logistics specific open-source modules. This approach is in line with several initiatives from governments to encourage the digital platform-based disruption and growth of traditional industries [10]. Further, the project's approach to offer selectable components fits the modular design of digital platforms. It allows for customized but industry-standard establishing digital platforms if most logistics companies adopt them [11]. This empowerment of the (incumbent) European logistics companies is relevant to ensure their success and prevent the logistics industry's disruption by "newcomers" like Uber in the taxicab industry or Airbnb in the hotel industry $[10,12]$. These became winner-takes-all markets in which only one or two digital platforms become dominant at the expense of the industry's incumbent companies. Further, there is a rich 
field of start-ups in the logistics industry that challenge incumbents through digital business models [11].

Next to the offered IT expertise and ready-to-use open-source module solutions, logistics companies would benefit from additional platform design and strategy support. Thus, this paper introduces a new and guiding artifact, the Platform Alignment Canvas (PAC), assisting prospective platform owners in designing digital platforms and corresponding business models. The vast landscape of existing platform canvases validates the need for platform canvases in practice. However, the existing canvases only cover detailed platform-specific design elements while lacking the big picture definition: the platform's purpose and role in the context of the company's overall vision and goals. This big picture description is essential to ensure this global alignment and to benefit from the platform. Thus, the PAC's specialty is this context level, meaning that the platform's purpose guides the implementation, evaluates the platform's progress in comparison to its initial purpose, and matches it with the platform's highlevel design knowledge [13]. So, the PAC considers the platform owner's purpose, the value created and exchanged, the involved stakeholders, and the crucial requirements to be met for its success. In short, the "why - purpose' and the 'what - platform and feature description' of a platform [14, 15].

The PAC is a Visual Inquiry Tool (VIT) (also referred to as design canvas) that enables the modularization of designable phenomena [13]. Due to digital platforms' complexity, one VIT is insufficient to cover a platform project from vision to departmentspecific implementation strategies (e.g., marketing and IT). Thus, we propose a hierarchization of VITs - a PAC kit - further modularizing the platform design. Here, the PAC only addresses the design levels 'why' and 'what'. To guide the corresponding aligned implementation, we envision additional VITs addressing domain-specific 'how' strategies. Accordingly, this paper and the artifact are part of a more extensive ongoing design study for platforms. This paper aims to answer the following research question:

Research Question: How to transform a traditional industry by supporting (incumbent) companies in designing and developing digital platforms?

The paper's structure: After the introduction, Section 2 outlines the state of the art of industry transformation via a digital platform. Section 3 illustrates the research design. The PAC gets introduced in Section 4. Section 5 demonstrates the applicability of the PAC before the paper finalizes with a conclusion and outlook.

\section{Designing Digital Platforms to Transform Industries}

Digital platforms are part of Industry 4.0 (also referred to as Industrial Internet of Things) [16]. Digital platforms are strategically important as they allow for vertical and horizontal connections across supply chains [16]. Further, they play a significant role in future company-level or even industry-level innovation [2, 17]. Thus, to allow for the successful adoption of Industry 4.0 measures, i.e., introducing a new digital platform, top management must define a new direction and its corresponding vision and derive an aligned company-wide implementation strategy [18].

Tiwana et al. define digital platforms as "(...) the extensible codebase of a software-based system that provides core functionality shared by the applications that interoperate with it and the interfaces through which they interoperate" [19 p. 676]. According to Cusumano et al., digital platforms fall into two categories: transaction and innovation platforms [4]. Transaction platforms enable an easy exchange of information, goods, and services between supply and demand (e.g., Uber, eBay, or Airbnb) [20, 21]. Innovation platforms enable third-party companies to add value to a core product or technology via complementary products (e.g., Microsoft's or Linux's operating systems) [22]. Integration platforms are the combination of transaction and innovation platforms in one single platform. Platforms mediate transactions between two distinct sides (two-sided) or more (multi-sided) [2] resulting in direct (same-side) and/or indirect (cross-side) network effects that significantly impact the decision of joining the platform for both the supply and demand-side [23].

Wallsten stated that, e.g., the "(...) "sharing economy" has turned traditionally underused assets into competitors to established industries" [24 p. 2]. This allows even new entrants to disrupt existing industries via digital platforms [24]. A well-known example is Uber which converted prior taxi drivers and people with a car and sufficient free time into contractors [12]. Thus, the taxicab industry got disrupted by ride-sharing platforms like Uber and Lyft, which did not need to obey the industry's strict regulations like fixed prices [24]. This works particularly well in commodity markets where customers focus on low prices and easy access and as little administration effort as possible. Thus, e.g., in the taxicab industry, customers do not care about brands, as long as they achieve their goals like getting from A to B to an acceptable price whenever needed. The same counts for the logistics industry. Currently, the logistics companies are in fierce and complex competition due to few differentiation potentials, only leaving room for a price war common in red ocean strategies $[25,26]$. Thus, the logistics industry might 
face a digital platform competition in a few years, excelling at offering transports from $\mathrm{A}$ to $\mathrm{B}$ at low costs and of reliably good and/or transparent/rateable quality following Uber's lead. Today, a few of the bigger incumbent logistics companies already do have digital platforms. So, the use case enables incumbent companies, especially SMEs with limited resources and internal IT expertise, with the IT modules and knowhow needed to expand into the digital services/platform market, enabling new and innovative business models.

Thus, this project chose to influence and drive the industry's transformation with the availability of industry-specific open-source components. The intention is to achieve standardization and compatibility with the potential of co-opetition, strengthening the incumbents' competitiveness. If successful, this mindset change could trigger new business models as licensable add-on improvements and services that could be integrated into the then existing digital platforms. This might eventually even open the door for open industry and open ecosystem collaboration opportunities [27]. These would lead to faster industry developments and potentially even to intercompany solution offers [28].

So, to convince logistics companies to engage in the project and integrate the offered open-source components, the project needs clear and convincing value propositions. Particularly supporting the companies' purpose of creating additional value for customers to ensure their survival in the long run via digital platforms [7]. As developing platforms is a complex endeavor consisting of multiple design levels (e.g., Governance [7] or Business Models [29]), many different internal and external stakeholders are inevitably involved [30, 31]. We propose digital platform design support to prevent incumbent companies from platform failure and ensure that their platforms' design levels and stakeholders are aligned. For business model development, the Business Model Canvas by Osterwalder and Pigneur [32] - today's most prominent VIT - is the standard for business model design. Thus, we derive that the project's incumbent companies would benefit greatly from a dedicated platform specific VIT to guide the platform design. To ensure alignment from 'vision to responsibility-fitting implementation plans', a hierarchy of platform VITs is necessary. It will stretch from common VITs that ensure the stakeholders' alignment to customized VITs supporting specific stakeholders/expert groups in defining and executing their particular tasks. For the alignment and orchestration of the $P A C$ kit, it is crucial to question the 'why (are we building a platform)?', 'what (is required and needs to be offered to be

\footnotetext{
${ }^{1}$ https://www.theplatformcanvas.com last-accessed: 13.06.2021
}

successful)?' before diving into 'how (must the platform be built to make it possible)?' [4, 29]. This differentiation demonstrates that at least three groups of experts must be part of the company's platform task force. First, the business expert controls the why ensuring that the platform's business model suits the company's overall goal and strategy. Second, the domain expert (in the project's case, the logistics experts) handles the what - defining the functionalities and requirements, ensuring that the platform successfully serves the industry's customers (and fellow providers). Third, the IT expert - in control of the how - defining and implementing, e.g., the platform architecture and boundary resources.

A Google search for 'platform canvases' shows that several canvases for (digital) platform design already exist (see, e.g., two examples of this paper's sample of ten platform canvases ${ }^{1,2}$ ). On average, each canvas consists of 12 building blocks, ranging from 8-17 building blocks. Two of these canvases are canvas kits meaning that they split the platform design into several canvases. All canvases focus primarily on platform actors, unique value propositions (UVP), transactions/ interactions, infrastructure/rules, KPIs/ metrics, and costs/revenues. The platform actors seem to attract special attention as some canvases ask for the definition of up to six different stakeholder groups. None of the found canvases addresses the first question, 'why'. However, the 'why' is crucial to ensure that the top management's vision finds reflection in the platform's purpose and guides and aligns its implementation company-wide $[18,33]$.

\section{Research Design}

Digital platform projects are designed and organized in large interdisciplinary teams [34-36]. As this paper aims at supporting these interdisciplinary projects, its artifact/result must facilitate and support a concise communication and strategic alignment of all involved stakeholders. VITs are known to reduce an artifact's design complexity by decomposing it into several inter-dependent building blocks [35] positioning it as a model regarding March and Smith's [37] classification of artifact types in design science research. To achieve the reduction of a digital platform's complexity, we chose VITs over more formal design methods. Furthermore, the intuitive visual design of VITs fosters discussion, brainstorming, and collaboration.

\footnotetext{
${ }^{2}$ https://www.canvasgeneration.com/canvas/platform-businessmodel-canvas/ last-accessed: 13.06.2021
} 


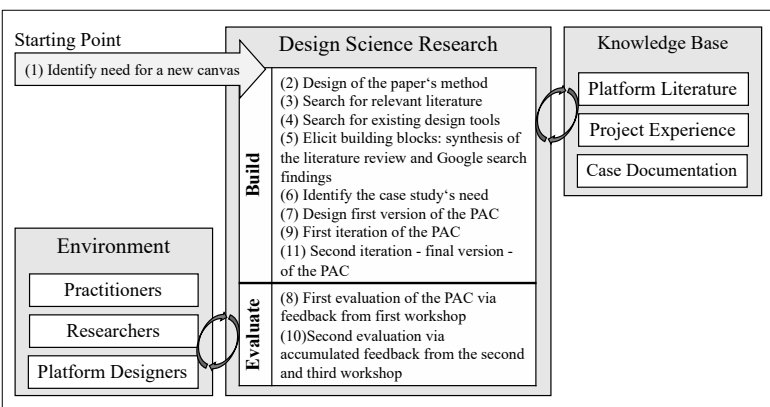

Figure 1: Research design based on Hevner [38]

As the PAC is a model, its design follows Hevner's three-cycle view (see Figure 1) [38]. We establish a link between the relevance, design, and rigor cycles by circling between conceptual literature work, platform design tools, project notes, and practitioners' feedback.

First, the case study triggers the need for a new platform VIT (usually called platform canvas) (relevance - step 1) as the existing platform VITs do not address the platform design's 'why' company's/owner's vision. Second, we define the paper's design method (design - step 2). We opt for a systematic literature review of high-quality journal publications and conference proceedings to generate a database of articles addressing platform design [39] (rigor - step 3). Third, we define the literature review strategy by ideating keyword combinations to find platform design knowledge in the literature (see Table 1). Fourth, we search through the most extensive database on scientific literature, Scopus, to look for papers in the Scholars' basket of eight journals, the topranked IS conferences ICIS, ECIS, and HICSS, and the premier conference on design science DESRIST. Especially, the HICSS conference had several VITspecific tracks (e.g., see [40]). Fifth, we find design knowledge in the extant literature and in taxonomies of digital platforms (e.g., see [41]). Sixth, we use Google to search for platform canvases (e.g., see the Platformdesigntoolkit ${ }^{3}$ ) to construct a database of ten platform canvases (rigor - step 4). The paper selection was driven by paper access and the applicability to the paper's research focus. Most papers detailed very specific platform-related questions (focusing on aspects of the platform's 'how'-level), which were too finegranular to be of relevance in this paper. To summarize, we generated 950 hits and selected 60 articles and platform canvases (see Table 1).

As our goal is to develop a VIT, we aggregate all essential 'why' and 'what' platform design elements. We use logical content aggregation to align the found design dimensions into higher-level categories (design - step 5) [42]. Here, we apply a combined approach of concept matrix and creative sessions [43]. Subsequently, we select existing and define new design elements - building blocks - based on the synthesis of higher-level categories. The PAC is intended to be used generically and in specific case settings. Thus, we match the case study requirements with potential building block candidates (step 6). The result is the initial version of the PAC (step 7).

Table 1: Literature Search Strategy

\begin{tabular}{|c|c|c|c|c|}
\hline Outlet & Strategy & Keywords & Hits & Selected \\
\hline AISeL & $\begin{array}{l}\text { Abstract } \\
\text { OR Title }\end{array}$ & $\begin{array}{l}\text { "platform”, } \\
\text { "taxonomy" }\end{array}$ & 38 & 11 \\
\hline EJIS & \multirow{12}{*}{$\begin{array}{l}\text { Title, } \\
\text { Abstract, } \\
\text { Key- } \\
\text { words }\end{array}$} & \multirow{5}{*}{$\begin{array}{c}\text { "platform } \\
\text { design" } \\
\text { "platform } \\
\text { development" }\end{array}$} & 22 & 0 \\
\hline ISJ & & & 22 & 3 \\
\hline ISR & & & 50 & 4 \\
\hline JAIS & & & 22 & 1 \\
\hline JIT & & & 20 & 4 \\
\hline JMIS & & \multirow{2}{*}{$\begin{array}{l}\text { "platform } \\
\text { method" }\end{array}$} & 34 & 1 \\
\hline JSIS & & & 7 & 0 \\
\hline MISQ & & \multirow{3}{*}{$\begin{array}{l}\text { "platform } \\
\text { canvas" }\end{array}$} & 40 & 1 \\
\hline ICIS & & & 158 & 8 \\
\hline ECIS & & & 222 & 8 \\
\hline HICSS & & \multirow{2}{*}{$\begin{array}{c}\text { platform } \\
\text { taxonomy", }\end{array}$} & 302 & 9 \\
\hline DESRIST & & & 3 & 0 \\
\hline $\begin{array}{l}\text { Google } \\
\text { Search }\end{array}$ & \multicolumn{2}{|c|}{ "platform canvas" } & 10 & 10 \\
\hline \multicolumn{3}{|c|}{ Summary } & 950 & 60 \\
\hline
\end{tabular}

In steps 8 and 10 (relevance), we evaluate the PAC via three workshops. Workshops are an accepted evaluation tool of artifacts as they capture the participant's qualitative feedback $[44,45]$. We had three interactive (online) sessions with project team members (2), project leads (2), and an associated industry partner (1). In each session, the users receive the PAC (see Figure 2) with the corresponding concept table (see Table 2). The concept table uses guiding questions to detail the PAC's building blocks and proposes its order of completion and instructs on using it. First, the users have five minutes to get acquainted with the PAC before describing their first impression. Then they fill out the PAC by themselves and present their results. Third, they provide final (independent) feedback. Fourth, we state our intentions and ask for further suggestions of improvement. The gathered feedback guides the design iterations. Based on the first workshop, our team members' feedback, we iterate the PAC's design and concept table (design - step 9). Then, we evaluate the PAC's second version twice (once with two project leads and once with an industry partner) (step 10). Section 5 presents the PAC's third and, for now, final version, including the second iteration (design - step 11; see Figure 2).

\footnotetext{
${ }^{3}$ https://platformdesigntoolkit.com/ last-accessed: 14.06.2021
} 


\section{Introduction of the Platform Alignment Canvas (PAC)}

Existing canvases focus on the platform's 'what' and 'how': stakeholders, UVP, transactions, infrastructure, KPIs, and costs and revenues. Whereas most literature focuses on specific how-considerations, some, e.g., Schreieck et al. [7], and Staykova and Hedman [46], also research 'what'-elements. Next to the abovementioned elements, they address a platform's competitiveness, performance, openness, governance, and trust. But, none of these considerations aligns the platform with the company's overall and the dedicated platform vision. We add four newly defined building blocks. The first two address the new why-level, and the other two add further what-descriptions: (1) purpose for the owner, (2) problems to be solved, (3) platform type, and (4) requirements:

(1) Purpose: Without considering the company's overall vision, it cannot be ensured nor regularly checked whether the platform actually achieves the intended results.

(2) Problems: Understanding the market's/users' (of both the supply- and demand-side) problems to ensure the platform's value.

(3) Platform Type: Based on the type, several requirements can be pre-determined.

(4) Requirements: It defines the platform's 'must haves' to ensure its success. This summary of the 'whats' enables the transition to the next hierarchy level of the envisioned PAC kit: the 'how' canvases. These canvases design and support expert groupspecific implementation strategies (e.g., one dedicated VIT for the IT implementation describing the platform's architecture and boundary resources).

\subsection{The PAC's Building Blocks}

The synthesis of the existing canvases and the literature findings is the basis of our VIT. As VITs depend on a parsimonious design, the PAC can only integrate the most relevant design elements [35]. Therefore, we defined and selected ten building blocks (see Table 2). Each building block is further defined by two to four guiding questions, which were logically abstracted from the building blocks. The questions specify the building block's purpose and meaning and were refined in discussions with users of the PAC to ensure their correct interpretation and application.
Table 2: Concepts of the PAC

\begin{tabular}{|c|c|c|c|}
\hline \multicolumn{3}{|c|}{ Building Block } & \multirow[b]{2}{*}{$\begin{array}{l}\text { Guiding Questions } \\
\text { - Who is the owner of the platform (e.g., } \\
\text { the company)? } \\
\text { - What is the company's vision (e.g., } \\
\text { growth, increased market share, enabling } \\
\text { future innovations)? } \\
\text { - How will the platform support the } \\
\text { owner's vision? }\end{array}$} \\
\hline \multirow{3}{*}{$\sum^{2}$} & n & $\begin{array}{l}\text { Purpose for } \\
\text { the Owner }\end{array}$ & \\
\hline & 0 & $\begin{array}{c}\text { Problems to } \\
\text { be solved }\end{array}$ & $\begin{array}{l}\text { - Which customer segment/market does the } \\
\text { platform intend to serve? } \\
\text { - What are the customer segment's } \\
\text { problems (e.g., jobs to be done, current } \\
\text { gains and pains)? }\end{array}$ \\
\hline & $\begin{array}{l}: \\
0 \\
0 \\
\infty \\
\infty\end{array}$ & $\begin{array}{l}\text { UVP of the } \\
\text { Platform }\end{array}$ & $\begin{array}{l}\text { - What is the platform's unique value } \\
\text { proposition (e.g., how does it address the } \\
\text { customer segment's problems)? } \\
\text { - How will the platform differentiate itself } \\
\text { from other platforms? } \\
\text { - How to protect this advantage? }\end{array}$ \\
\hline \multirow{7}{*}{$\frac{\bar{J}}{3}$} & $\begin{array}{l}\text { 至 } \\
\infty \\
\infty \\
\infty\end{array}$ & $\begin{array}{l}\text { Platform } \\
\text { Type }\end{array}$ & $\begin{array}{l}\text { - Which platform type(s) fit the UVP best } \\
\text { (e.g., transaction (marketplace for supply } \\
\text { and demand), innovation (involvement of } \\
3^{\text {rd }} \text { party developers) or integration (mix } \\
\text { of transaction and innovation))? } \\
\text { - How many platform sides are involved? } \\
\text { - How to describe the stakeholders best } \\
\text { (e.g., B2B, B2C or P2P)? } \\
\text { - Where do the transactions take place } \\
\text { (e.g., app or web application)? }\end{array}$ \\
\hline & $n$ & Providers & $\begin{array}{l}\text { - Who helps to generate platform value? } \\
\text { - What do the providers offer (e.g., } \\
\text { platform foundation or modules)? } \\
\text { - How do the providers benefit? }\end{array}$ \\
\hline & $\theta$ & Customers & $\begin{array}{l}\text { - For whom is it offering value? } \\
\text { - How do the customers benefit? } \\
\text { - What do they offer in exchange? }\end{array}$ \\
\hline & 茫 & Transaction & $\begin{array}{l}\text { - Which kinds of transactions are possible } \\
\text { (e.g., services for money)? } \\
\text { - How to offer value for stakeholders? } \\
\text { - Does the owner steer the transaction? }\end{array}$ \\
\hline & n & Costs & $\begin{array}{l}\text { - Which direct costs incur (e.g., salaries)? } \\
\text { - Which indirect costs incur (e.g., rent, } \\
\text { community management)? }\end{array}$ \\
\hline & D & Revenue & $\begin{array}{l}\text { - What are revenue options for the owner } \\
\text { (e.g., short- vs. long-term)? } \\
\text { - How do the providers benefit and } \\
\text { generate revenues for themselves? }\end{array}$ \\
\hline & 党 & $\begin{array}{l}\text { Require- } \\
\text { ments }\end{array}$ & $\begin{array}{l}\text { - How does the platform ensure to solve } \\
\text { the customer's problem? } \\
\text { - What are functional requirements to } \\
\text { ensure stakeholder satisfaction? (e.g., } \\
\text { roles \& rights, profiles, etc.) }\end{array}$ \\
\hline
\end{tabular}

The 'how'-level will be derived based on the PAC's requirements - the final building block. For each expert group/domain, specialized VITs will be developed to ensure the alignment from the owner's perspective and the overall platform description (the PAC) to the final platform implementation via customized implementation strategies.

Legend: $\mathrm{S}=$ Supply-side, D = Demand-Side, $\mathrm{S} \& D$ Fit $=$ Supply and Demand Fit 
The top three building blocks explain ' $w$ hy are we building a platform?', asking for the motivation of designing a platform (purpose for the platform owner and the chosen market's problems to be solved) and linking it to the platform's UVP.

The remaining seven building blocks describe 'what is required and needs to be offered to be successful?'. First, the chosen platform type defines the platform configuration (e.g., transaction to innovation platform), the selection of involved platform sides (twoor multi-sided), and stakeholder descriptions (e.g., businesses or customers), as well as the access technology. Next, the PAC asks for clarification of the served providers (adding value) and customers (receiving value) and the kinds of transactions and relationships supported between the supply and demand side. To assess the likelihood of the platform's success and rentability, it is essential to paint a realistic picture of the owner's costs of developing and running the platform and its community. These costs must be covered by the platform's revenue potentials to get started with the platform project under review of the PAC. The final building block - requirements - acts as a summary of all the what-requirements the platform needs to adhere to to ensure that it meets its UVP. Further, it sets the stage for deriving suitable implementation strategies in additional platform VITs, which will address 'how must the platform be built to make it possible?'.

\subsection{From Concept Table to Visual Inquiry Tool}

As the PAC (see Figure 2) is a VIT, the design principles by Avdiji et al. [35] guide the design process from table to canvas (see Table 3). Furthermore, we use these design principles as codified, priorly generated design knowledge intended for reuse [47]. Besides, we draw inspiration for the visual design from best practices (e.g., see BMC [32]). Finally, using and instantiating these design principles is part of the practical ethos of design science [48].

\section{Illustrative Application and Evaluation of the Platform Alignment Canvas}

We show the applicability of the PAC through an illustrative application with project leads of the paper's logistics case study (see Figure 2) [49]. Since the start of the project ten months ago, brainstorming, project definition, and communication took place via (online) meetings, documents, and presentations. This was the first time the project was defined with a VIT.

\section{Table 3: Design principles for Visual Inquiry} Tool design [35]

\begin{tabular}{|c|c|c|}
\hline \multicolumn{2}{|c|}{ Design Principle } & Instantiation \\
\hline \multirow{3}{*}{ 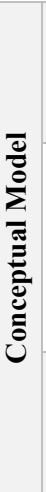 } & Frame & $\begin{array}{l}\text { The PAC examines the platform from an } \\
\text { internal perspective. The building blocks are } \\
\text { mutually exclusive and cover all relevant } \\
\text { aspects. }\end{array}$ \\
\hline & $\begin{array}{c}\text { Rigor \& } \\
\text { Relevance }\end{array}$ & $\begin{array}{l}\text { The building blocks are based on the } \\
\text { literature corpus on platform design and } \\
\text { findings from the inductive analysis of } \\
\text { platform design tools. Complementarily, the } \\
\text { PAC gets tested by practitioners who validate } \\
\text { its applicability. }\end{array}$ \\
\hline & Parsimony & $\begin{array}{l}\text { The evaluation cycles show that the PAC is } \\
\text { simple and easy to use. It has only ten } \\
\text { building blocks which still makes it } \\
\text { parsimonious. }\end{array}$ \\
\hline \multirow{3}{*}{ 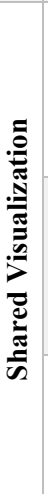 } & Functionality & $\begin{array}{l}\text { The PAC's building blocks are empty. The } \\
\text { platform design will be done with sticky } \\
\text { notes. This allows for creative hypothesizing } \\
\text { and easy modifications based on new } \\
\text { learnings. }\end{array}$ \\
\hline & Arrar & $\begin{array}{l}\text { The building blocks are organized from the } \\
\text { top (why) to the bottom (what) and from the } \\
\text { left (supply) to the right (demand). } \\
\text { The practitioners identified and followed the } \\
\text { building blocks' logical flow. }\end{array}$ \\
\hline & Facilitation & $\begin{array}{l}\text { To ease each building block's understanding, } \\
\text { they are all named and include a } \\
\text { corresponding metaphor represented by an } \\
\text { icon. }\end{array}$ \\
\hline \multirow{3}{*}{ 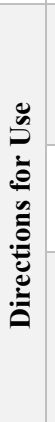 } & Ideation & $\begin{array}{l}\text { The PAC comes together with a concept table } \\
\text { detailing directions for use. It promotes } \\
\text { collaborative and heterogenous team use to } \\
\text { enable } 360^{\circ} \text { results. }\end{array}$ \\
\hline & Prototyping & $\begin{array}{l}\text { Guiding questions and sticky notes help the } \\
\text { designers ideate and select hypotheses for } \\
\text { each building block. }\end{array}$ \\
\hline & Presentation & $\begin{array}{l}\text { The PAC allows for tangible marks } \\
\text { supporting the further planning and } \\
\text { implementation of the designed platform in a } \\
\text { similar fashion to other canvases (e.g., see } \\
\text { [36] or [50]). }\end{array}$ \\
\hline
\end{tabular}

\subsection{Case Study Description}

The case study, the Silicon Economy Logistics Ecosystem, is a consortium-driven platform aiming at establishing an industry-standard in the European logistics industry. It shall provide all industry stakeholders with the tools and open source components to build their own platforms: architecture, modules, services, and a business model portfolio. The European logistics industry is unique and complex as it struggles with high competition, low margins, and a fierce price war due to its offerings' missing differentiation possibilities [26, 51]. This competition pushes industry stakeholders to value their independence and avoid 


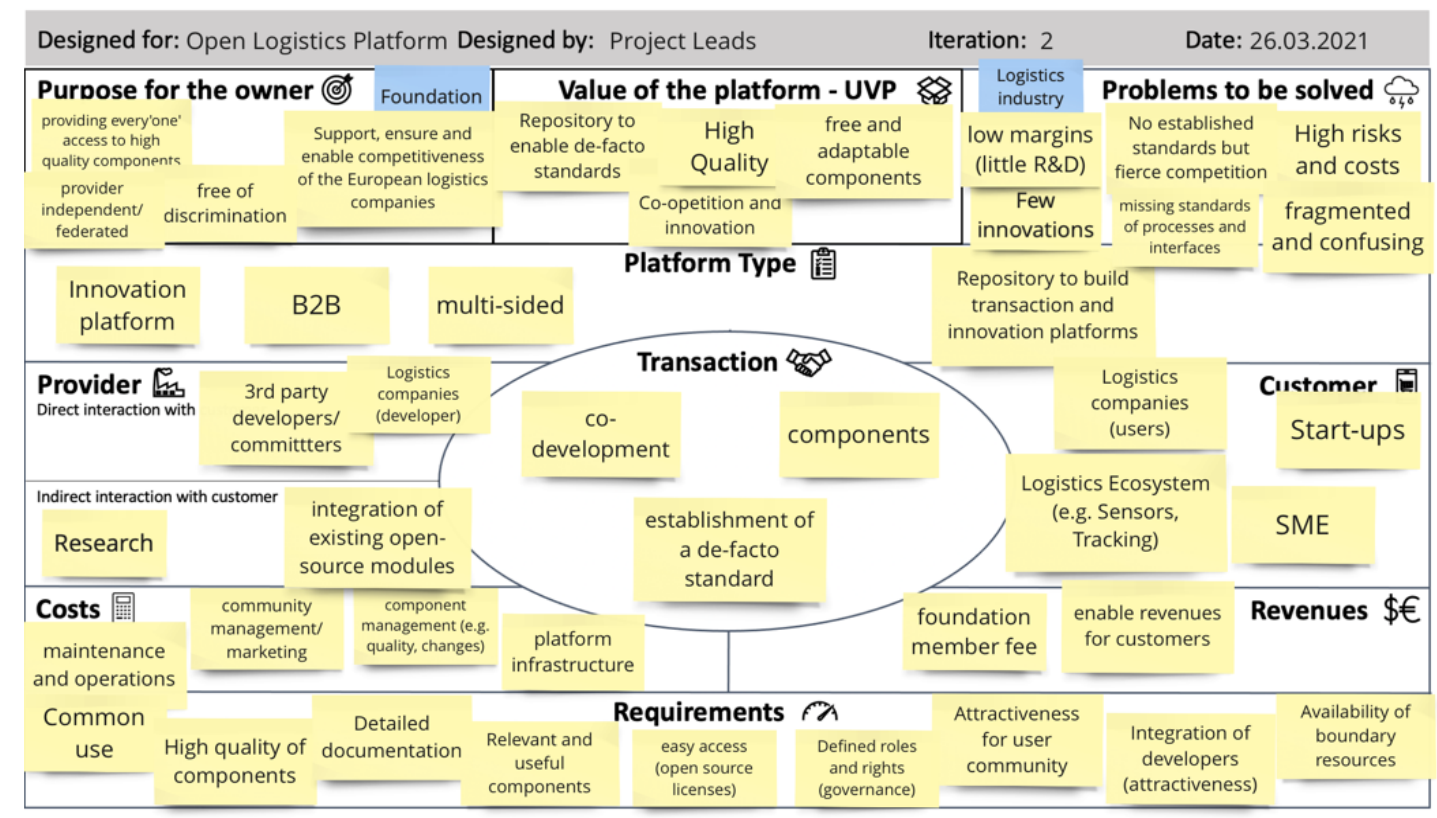

Figure 2: Demonstration of the Platform Alignment Canvas (PAC)

strengthening a competitor's position. Therefore, there is little incentive to adopt external solutions and establish industry-wide standards. Nevertheless, to protect themselves from foreign competitors, they need to prepare for the next wave of innovations - platformenabled business models.

The case study combines three levels of complexity. First, the absence of a dominating platform owner requires the orchestration of a host of various stakeholders that are peers [52]. Second, the case study concerns a platform to build platforms - a repository consisting of open-source modules to enable companies to build customized platforms for themselves. Thus, the platform must support many different needs, requirements, and functionalities to achieve value for the variety of 'customized platform' owners. It is a perfect example of a complex platform project and thus a great test for the PAC. Third, all components are to be developed and offered open-source. The open-source choice requires the creation of a community to support and maintain the long-term development efforts. These conditions must be adequately understood, aligned, and managed to ensure that the project's vision of a provider-independent industry standard can be achieved.

\subsection{Evaluation of the Platform Alignment Canvas}

We received feedback from three workshop groups in two evaluation cycles. All workshop participants considered the PAC's visual design professional.
Further, they highlighted the usability of the PAC, which, conjointly with the guiding questions formulated in Table 2, was seen as straightforward, logically designed, and easy to use and understand. They suggested minor changes regarding the PAC's design and usability (e.g., new/renamed building blocks and complementary and/or slightly reframed questions), that we incorporated in the design iterations.

Following Avdiji et al. [35], the PAC asks for concise descriptions of the platform's design components written down on sticky notes (see Figure 2). During the workshops, this level of precision, especially regarding the platform owner's purpose and its fit to the platform's UVP, revealed diverging views, interpretations, and prioritizations among the participants. These led to interesting discussions which would not have been triggered by other platform canvases neglecting the 'why' level. However, it was striking that the application of the PAC established and fostered a shared project understanding: It is a consortium-driven innovation platform acting as a multi-sided repository offering the players of the European logistics industry open-source software components to establish a de-facto standard by simplifying the players'/users' digital platform development. Thus, users benefit from the provided resources, efforts, and expertise decreasing their workload, expenditures, and costs.

To conclude, the PAC's integration of the why ensures the platform's fit to the owner's overall vision. Further, it aligns involved stakeholders (highlighting why we named the VIT 'platform alignment canvas'). 
Nevertheless, it became evident that the envisioned $P A C$ kit is necessary to ensure that the owner's vision and platform design get further detailed and translated into suitable implementation strategies while ensuring continuous alignment. Besides, the practitioners highlighted that the PAC also acts as a 'checklist'.

The application and feedback of the PAC led to the following changes: we added the grey header, we deleted the initially present guiding questions in light grey (one per building block), changed two building block names (purpose of the platform to the purpose for the owner and producer to provider), added one building block (problems to be solved) and split one building block in half to increase precision (provider). The table's guiding questions were refined and updated according to the changes of the PAC. The PAC's previously integrated guiding questions were deleted as it led users to neglect the concept table.

\subsection{The Platform Alignment Canvas' Role in supporting Industry Transformation}

As industry transformation is often driven by digital platforms companies need to adapt accordingly to survive. However, most platforms fail as normally only a few digital platforms dominate the market [12]. The average lifetime of a platform is less than five years [4]. Yoffie et al. has identified the four most striking mistakes, which are mispricing, missing trust, forgetting about the competition, and entering too late [4]. Thus, if a governmental funded project strives to disrupt and to progress a traditional industry, it is not sufficient to make a modularized open-source repository available. It also needs to support and educate the (incumbent) companies in designing a sound digital platform and corresponding business models. Here, it is critical that companies act and make informed decisions rather than focusing on incremental adaptations, which feel less risky but will be insufficient to survive the disruption [18].

The PAC serves as a framework to reflect and define on all important (strategic) aspects to ensure that companies do not rush into the implementation of unsophisticated platform designs but reflect on the problems the platform shall solve or the opportunities it shall generate. This, e.g., includes defining a unique value proposition differentiating own offers from competitors'. We can only highlight the observed benefit of the PACs power to structure and ask for a common and shared understanding of the platform's purpose while reducing the risk of forgetting important considerations. Once the purpose is understood and communicated, we propose to engage in an agile implementation strategy to continuously adapt the milestones and measures according to the new learnings. To support this complete process, we plan to design additional VITs that will guide the expert groupspecific strategies allowing for continuous as-is and tobe tracking and iterations.

\section{Contributions, Limitations, and Outlook}

As platformization hits and disrupts (traditional) industries and most platforms fail, we identified the need for a new VIT guiding practitioners' complex digital platform design. It helps to prevent mistakes already in the platform design phase. We added the platform owner's context - 'why' - to design the platform's 'what'-description. This new perspective enables practitioners to design platforms that are in sync with their overall vision and respectively to evaluate the platform's success.

Our work provides several contributions to research. First, the $\mathrm{PAC}$ is a tool for the systematic analysis of design knowledge on digital platforms. It can be used to analyze, compare and optimize digital platforms. However, the main goal is to support the design of platforms. The PAC's ten building blocks guide step by step from vision to a designed digital platform description. The PAC is an applied and iterated VIT assisting the platform design and stakeholder alignment in terms of practical contributions. It focuses on questioning and designing the 'why' and 'what' of the platform. This understanding of the platform and the corresponding requirements will be translated into domain-specific implementation design canvases in the next hierarchy level of the envisioned $P A C$ kit. It advances the systematic extension of design knowledge on digital platforms. Platform designers can use it to define, establish, and agree on new platform visions and promising business models. Additionally, the canvas acts as a 'checklist', requiring its users to consider the most critical platform design elements.

Our research comes with some limitations. First, the designed artifact needs to be further evaluated. Although we developed the PAC to represent digital platforms generally, we evaluated and designed the canvas conjointly with project members and an associated industry partner in one dedicated project environment. Thus, it allowed for a deep dive analysis of one specific project. However, further evaluation cycles should analyze and validate the general applicability of the PAC. Accordingly, extending the study's frame to additional projects and industries or collecting empirical data through desk research are potential roads for continuing the development of the PAC. Second, avenues for further research include the design of a portfolio of VITs tailored both generically to digital platforms and specifically to the paper's use case. 
Third, we are aware that we probably did not find and consider all of the relevant literature.

\section{Acknowledgement}

The project "Silicon Economy Logistics Ecosystem" is funded by the Federal Ministry of Transport and Digital Infrastructure.

\section{References}

[1] Gawer, A. and M.A. Cusumano, "Industry Platforms and Ecosystem Innovation", Journal of Product Innovation Management, 31(3), 2013, pp. 417-433.

[2] Reuver, M. de, C. Sørensen, and R.C. Basole, "The Digital Platform: A Research Agenda", Journal of Information Technology, 33(2), 2018, pp. 124-135.

[3] Schreieck, M., E. Clemons, M. Wiesche, and H. Krcmar, Competing with Giant Platform Operators: An Analysis of Which Traditional Manufacturing Companies are at Risk from Strategic Dependence on Other Companies' Platforms in the Emerging Era of the Internet of Things, 2019.

[4] Yoffie, D.B., A. Gawer, and M.A. Cusumano, "A study of more than 250 platforms a reveal why most fail", Harvard Business Review, 2019.

[5] Cusumano, M.A., D.B. Yoffie, and A. Gawer, "The future of platforms", MIT Sloan Management Review, 61(3), 2020, pp. 46-54.

[6] Sebastian, I.M., K.G. Moloney, J.W. Ross, N. Fonstad, C. Beath, and M. Mocker, "How big old companies navigate digital transformation", MIS Quarterly Executive, 16, 2017, pp. 197-213.

[7] Schreieck, M., M. Wiesche, and H. Krcmar, "Design and Governance of Platform Ecosystems - Key Concepts and Issues for Future Research", in Proceedings of the 24th European Conference on Information Systems, Istanbul: Turkey. 2016.

[8] Cross, N., "Design Research: A Disciplined Conversation", Design Issues, 15(2), 1999, pp. 5-10.

[9] https://www.bvl.de/service/zahlen-daten-fakten/umsatzund-beschaeftigung, accessed 12-24-2020.

[10] Hänninen, M. and L. Paavola, "Digital Platforms and Industry Change", in Society as an Interaction Space: A Systemic Approach, H. Lehtimäki, P. Uusikylä, and A. Smedlund, Editors. 2020. Springer Singapore: Singapore.

[11] Möller, F., H. Bauhaus, C. Hoffmann, C. Niess, and B. Otto, "Archetypes of Digital Business Models in Logistics Start-Ups", in Proceedings of the 27th European Conference on Information Systems, Uppsala and Stockholm: Sweden. 2019.

[12] Kenney, M. and J. Zysman, "The Rise of the Platform Economy", Issues in Science and Technology, 32(3), 2016, pp. 61-69.

[13] Vom Brocke, J., R. Winter, A. Hevner, and A. Maedche, "Accumulation and Evolution of Design Knowledge in Design Science Research - A Journey Through Time and Space", Journal of the Association for Information Systems, 21, 2020, pp. 520-544.
[14] Hamel, G., "The why, what, and how of management innovation", Harvard Business Review, 84(2), 2006, p. 72.

[15] Sinek, S., Start with Why: How Great Leaders Inspire Everyone to Take Action, Penguin Publishing Group, 2009.

[16] Schmidt, M.-C., J.W. Veile, J.M. Müller, and K.-I. Voigt, "Kick-Start for Connectivity: How to Implement Digital Platforms Successfully in Industry 4.0", Technology Innovation Management Review, 9(10), 2019, pp. 5-15.

[17] Gawer, A., "Bridging Differing Perspectives on Technological Platforms: Toward an Integrative Framework", Research Policy, 43(7), 2014, pp. 1239 1249.

[18] Steffen, B. and S. Boßelmann, "GOLD: Global Organization aLignment and Decision - Towards the Hierarchical Integration of Heterogeneous Business Models", in International Symposium on Leveraging Applications of Formal Methods. 2018. Springer International Publishing: Cham.

[19] Tiwana, A., B. Konsynski, and A.A. Bush, "Platform Evolution: Coevolution of Platform Architecture, Governance, and Environmental Dynamics", Information Systems Research, 21(4), 2010, pp. 675-687.

[20] Guggenberger, T., F. Möller, K. Boualouch, and B. Otto, "Towards a Unifying Understanding of Digital Business Models", in Proceedings of the 24th Pacific Asia Conference on Information Systems, Dubai: UAE. 2020.

[21] Asadullah, A., I. Faik, and A. Kankanhalli, "Digital Platforms: A Review and Future Directions", in Proceedings of the 22nd Pacific Asia Conference on Information Systems, Yokohama: Japan. 2018.

[22] Evans, P. and A. Gawer, The Rise of the Platform Enterprise: A Global Survey, The Emerging Platform Economy Series(No. 1), 2016.

[23] Gawer, A. and M.A. Cusumano, "Industry Platforms and Ecosystem Innovation", Journal of Product Innovation Management, 31(3), 2014, pp. 417-433.

[24] Wallsten, S., "The competitive effects of the sharing economy: how is Uber changing taxis", Technology Policy Institute, 22, 2015, pp. 1-21.

[25] Kim, W.C. and R. Mauborgne, "Red ocean traps", Harvard Business Review, 93(3), 2015, pp. 68-73.

[26] van Marwyk, K. and S. Treppte, 2016 logistics study on digital business models, 2016.

[27] Saebi, T. and N.J. Foss, "Business models for open innovation: Matching heterogeneous open innovation strategies with business model dimensions", European Management Journal, 33(3), 2015, pp. 201-213.

[28] Eisenmann, T.R., "Managing proprietary and shared platforms", California Management Review, 50(4), 2008, pp. 31-53.

[29] Täuscher, K. and S.M. Laudien, "Understanding Platform Business Models: A Mixed Methods Study of Marketplaces", European Management Journal, 36(3), 2018, pp. 319-329.

[30] Staykova, K.S. and J. Damsgaard, "A Typology of MultiSided Platforms: The Core and the Periphery", in Proceedings of the 23rd European Conference on Information Systems, Münster: Germany. 2015. 
[31] Smedlund, A. and H. Faghankhani, "Platform Orchestration for Efficiency, Development, and Innovation", Proceedings of the Annual Hawaii International Conference on System Sciences, 2015March, 2015.

[32] Osterwalder, A. and Y. Pigneur, Business Model Generation: A Handbook for Visionaries, Game Changers, and Challengers, Wiley, 2013.

[33] Steffen, B. and B. Steffen, "Asking Why", in 10th International Symposium on Leveraging Applications of Formal Methods, ISoLA 2021, Rhodes: Greece. 2021.

[34] Chandra Kruse, L. and J. Nickerson, "Portraying Design Essence", Proceedings of the 51st Hawaii International Conference on System Sciences, 2018, pp. 4433-4442.

[35] Avdiji, H., D.A. Elikan, S. Missonier, and Y. Pigneur, "A Design Theory for Visual Inquiry Tools", Journal of the Association for Information Systems, 21(2), 2020, pp. 695-734.

[36] Elikan, D.A. and Y. Pigneur, "A visual inquiry tool for brand identity", in Proceedings of the 52nd Hawaii International Conference on System Sciences, Hawaii: USA. 2019.

[37] March, S.T. and G.F. Smith, "Design and Natural Science Research on Information Technology", Decision Support Systems, 15(4), 1995, pp. 251-266.

[38] Hevner, A., "A Three Cycle View of Design Science Research", Scandinavian journal of information systems, 19(2), 2007, pp. 87-92.

[39] Vom Brocke, J., A. Simons, B. Niehaves, B. Niehaves, K. Riemer, R. Plattfaut, and A. Cleven, "Reconstructing the Giant: On the Importance of Rigour in Documenting the Literature Search Process", in Proceedings of the 17th European Conference on Information Systems, Verona: Italy. 2009.

[40] Avdiji, H., D.A. Elikan, S. Missonier, and Y. Pigneur, "Designing Tools for Collectively Solving Ill-Structured Problems", in Proceedings of the 51st Hawaii International Conference on System Sciences, Hawaii: USA. 2018

[41] Hermes, S., J. Kaufmann-Ludwig, M. Schreieck, J. Weking, and M. Böhm, "A Taxonomy of Platform Envelopment: Revealing Patterns and Particularities", in Proceedings of the 2020 Americas Conference on Information Systems, Salt Lake City: USA. 2020.

[42] Koppenhagen, N., O. Gaß, and B. Müller, "Design Science Research in Action - Anatomy of Success Critical Activities for Rigor and Relevance", in Proceedings of the 20th European Conference on Information Systems, Barcelona: Spain. 2012.

[43] Webster, J. and R.T. Watson, "Analyzing the Past to Prepare for the Future: Writing a Literature Review",
MIS Quarterly: Management Information Systems, 26(2), 2002, pp. xiii-xxiii.

[44] Thoring, K., R. Mueller, and P. Badke-Schaub, "Workshops as a Research Method: Guidelines for Designing and Evaluating Artifacts Through Workshops", in Proceedings of the 53rd Hawai Conference on System Sciences. 2020: Hawaii: USA.

[45] Åkesson, M., K. Kautz, and C. Ihlström Eriksson, "Engaged Design Science: Developing Design Visions for the Future E-Newspaper", in Proceedings of the 31st International Conference on Information Systems, St. Louis: USA. 2010.

[46] Staykova, K.S. and J. Hedman, "In the Search of New Perspective on Electronic Marketplaces", in Proceedings of the 27th European Conference on Information Systems, Uppsala and Stockholm: Sweden. 2019.

[47] Chandra Kruse, L., S. Seidel, and S. Gregor, "Prescriptive Knowledge in IS Research: Conceptualizing Design Principles in Terms of Materiality, Action, and Boundary Conditions", in Proceedings of the 48th Hawaii International Conference on System Sciences, Hawaii: USA. 2015.

[48] Iivari, J., Hansen, Perlt, Magnus Rotvit, and A. HajBolouri, "A Framework for Light Reusability Evaluation of Design Principles in Design Science Research", in Proceedings of the 13th International Conference on Design Science Research in Information Systems and Technology, Chennari: India. 2018.

[49] Peffers, K., M. Rothenberger, T. Tuunanen, and R. Vaezi, "Design Science Research Evaluation", in Design Science Research in Information Systems. Advances in Theory and Practice, K. Peffers, M. Rothenberger, and B. Kuechler, Editors. 2012. Springer Berlin Heidelberg: Berlin, Heidelberg.

[50] Schoormann, T., D. Behrens, M. Fellmann, and R. Knackstedt, "On Your Mark, Ready, Search: A Framework for Structuring Literature Search Strategies in Information Systems", in Proceedings of the 16th International Conference on Wirtschaftsinformatik, Essen: Germany (Digital). 2021.

[51] Bauer, I. and A. Wortman, Transport and logistics barometer: 2020 mid-year analysis of M\&A deals, joint ventures and strategic alliances in the transport and logistics industry, 2020.

[52] Hermes, S., N. Töller, A. Hein, and J. Weking, "Gaining Control over Critical Platforms: A Comparative Case Study of European Consortia", in Proceedings of the 28th European Conference on Information Systems, An Online AIS Conference. 2020. 